\title{
Variation Among Isolates of Fusarium graminearum Associated with Fusarium Head Blight in North Carolina
}

Scott L. Walker, Graduate Research Assistant, Department of Plant Pathology and Crop Science, Steven Leath, USDA-ARS and Professor, Department of Plant Pathology; Winston M. Hagler, Jr., Professor, Department of Poultry Science; and J. Paul Murphy, Professor, Department of Crop Science, North Carolina State University, Raleigh, 27695-7616

\begin{abstract}
Walker, S. L., Leath, S., Hagler, W. M., Jr., and Murphy, J. P. 2001. Variation among isolates of Fusarium graminearum associated with Fusarium head blight in North Carolina. Plant Dis. $85: 404-410$

Fusarium head blight (FHB) can reduce yield of wheat and decrease the value of harvested grain by accumulation of detrimental toxins. Understanding the variability of the fungal population associated with infection could improve disease control strategies. Sixty-six isolates of Fusarium graminearum associated with FHB were collected in North Carolina and tested for in vitro growth rate, in vitro production of deoxynivalenol (DON) and zearalenone, and pathogenicity on three cultivars of soft red winter wheat. Significant differences among isolates were found for all three traits. Randomly Amplified Polymorphic DNA (RAPD) analysis revealed high levels of genotypic diversity among isolates. Isolates of $F$. graminearum, $F$. culmorum, and F. avenaceum acquired from the Pennsylvania State University Fusarium Center were included for comparison in all tests. In vivo levels of DON were measured for the five isolates associated with the highest levels of disease and the five isolates associated with the lowest levels of disease, and no significant differences were found. However, all ten isolates produced detectable levels of DON in vivo. Mean disease ratings ranged from 3.4 to $96.4 \%$, in vitro (DON) levels ranged from 0 to $7176.2 \mathrm{ppm}$, and zearalenone ranged from 0 to $354.7 \mathrm{ppm}$, among isolates. A multiple regression model using in vitro growth, in vitro DON, and zearalenone production, collection location, wheat cultivar of isolate origin, plot, tillage conditions, and previous crop as independent variables and percent blighted tissue as the dependent variable was developed. The cumulative $R^{2}$ value for the model equaled 0.27 with in vitro rate of growth making the largest contribution. Analysis of phenotype and genotype among isolates demonstrated diversity in a single plot, in a single location, and in North Carolina. Genotypic and phenotypic diversity were significant under both conventional and reduced tillage conditions, and diversity was high regardless of whether the previous crop had been a host or non-host for $F$. graminearum. These data indicate a variable pathogen population of $F$. graminearum exists in North Carolina, and members of this population can be both highly pathogenic on wheat and produce high levels of detrimental toxins, indicating a potential threat for problems with FHB within the state.
\end{abstract}

Additional keyword: resistance

Fusarium head blight (FHB) or wheat scab is a seed and head disease characterized by bleaching of the wheat head, shriveled kernels, and accumulation of mycotoxins in grain $(1,2,5,7,12,15)$. Several species of Fusarium are associated with FHB. F. graminearum Schwabe (teleomorph Gibberella zeae (Schwein.) predominates in North America. F. culmorum and $F$. avenaceum are also responsible for FHB, but are less often implicated in the United States $(5,7,12)$. Infection can occur

Corresponding author: Steven Leath

E-mail: steven_leath@ncsu.edu

Accepted for publication 8 December 2000.

Publication no. D-2001-0209-01R

This article is in the public domain and not copyrightable. It may be freely reprinted with customary crediting of the source. The American Phytopathological Society, 2001. from the time of flowering to the soft dough stage, and is promoted by environmental factors such as warm temperatures and high humidity $(1,2,5,7,12,15)$. Gibberella zeae is also the causal agent of ear rot in maize and rotations of wheat and maize can increase the incidence of both diseases (12).

Fusarium isolates associated with FHB can produce mycotoxins, notably deoxynivalenol (DON) or vomitoxin, which poses a threat to humans and livestock when consumed in scabbed grain $(1,2,4,5,6$, $7,12,15)$. DON can cause feed refusal and higher-than-normal rates of abortion when ingested by livestock $(7,12)$. Fusarium species associated with FHB may also produce the toxin zearalenone which is reportedly linked to reduced weight gain and increased rates of abortion when ingested by swine (6). High levels of these mycotoxins reduce the value of grain and infested grain must be mixed with clean grain to reduce toxins to acceptable levels
(7). DON may function as a pathogenicity factor (4).

There is little evidence for pathogenic specialization within $F$. graminearum $(2,12)$. Differences in aggressiveness among isolates of $F$. graminearum, however, have been reported $(1,2,12)$. Reports of genotypic diversity among isolates of $F$. graminearum vary, with Bowden and Leslie (3) reporting high levels of variation in vegetative compatibility groups among $F$. graminearum isolates collected in the Midwestern United States, while Ouellet and Seifert (11) reported a low amount of genetic diversity among isolates of $F$. graminearum collected in Canada. Genetic characterization of European isolates of Fusarium species associated with FHB reveals a large amount of variation among isolates of some species $(9,14)$.

Bowden and Leslie (3) stated the population structure of $F$. graminearum is poorly understood, and a better understanding of spatial and temporal patterns of genetic diversity, potential for sexual and asexual reproduction, and selection pressures, could lead to better control strategies for FHB.

FHB is currently not a severe disease problem in North Carolina. Nevertheless, growers in the state have expressed concern over the potential for an increased problem with the disease due to the occurrence of severe outbreaks of the disease in the Midwestern United States. If an adequate source of inoculum is present, changes in cultural practices such as a trend toward reduced tillage may create the potential for FHB epidemics in areas where the disease is currently not a problem. The adequacy depends on the volume of inoculum, which is increased under reduced tillage, and its capability to cause disease. The purpose of this study was to provide data on pathogen diversity within North Carolina with regard to factors such as isolate aggressiveness and toxin production, and to determine both the diversity of the pathogen population and its potential to cause severe disease in the state.

\section{MATERIALS AND METHODS}

Isolate collection and phenotypic testing. Isolates were collected from wheat heads exhibiting symptoms of FHB in the Coastal, Piedmont, and Mountain regions of North Carolina during May and June 1996 (Table 1). Several isolates were collected at the Center for Environmental 
Table 1. Source of 66 isolates of Fusarium graminearum collected from wheat in North Carolina

\begin{tabular}{|c|c|c|c|c|c|c|}
\hline Isolate & County & $\begin{array}{c}\text { Geographical } \\
\text { designation }\end{array}$ & $\begin{array}{c}\text { Wheat cultivar from which } \\
\text { isolate originated }\end{array}$ & Plot & Tillage conditions & Previous crop \\
\hline NC 1 & Ashe & Mountain & Oasis $\times C 762^{\mathrm{a}}$ & 116 & Conventional $^{\mathrm{d}}$ & Maize \\
\hline $\mathrm{NC} 2$ & Ashe & Mountain & Oasis $\times C 762^{\mathrm{a}}$ & 116 & Conventional & Maize \\
\hline $\mathrm{NC} 3$ & Ashe & Mountain & C $8012 \times$ Gore $^{\mathrm{b}}$ & 78 & Conventional & Maize \\
\hline $\mathrm{NC} 4$ & Ashe & Mountain & $\mathrm{C} 8012 \times$ Gore $^{\mathrm{b}}$ & 78 & Conventional & Maize \\
\hline NC 5 & Ashe & Mountain & C $8012 \times$ Gore $^{\mathrm{b}}$ & 78 & Conventional & Maize \\
\hline NC 6 & Alamance & Piedmont & FFR 555 & Commercial $^{c}$ & Conventional & Soybean \\
\hline $\mathrm{NC} 7$ & Alamance & Piedmont & FFR 555 & Commercial $^{c}$ & Conventional & Soybean \\
\hline NC 8 & Alamance & Piedmont & FFR 555 & Commercial $^{c}$ & Conventional & Soybean \\
\hline NC 9 & Alamance & Piedmont & FFR 555 & Commercial $^{c}$ & Conventional & Soybean \\
\hline NC 10 & Davie & Piedmont & Karl & Commercial $^{\mathrm{c}}$ & Conventional & Maize \\
\hline NC 11 & Davie & Piedmont & Karl & Commercial $^{\mathrm{c}}$ & Conventional & Maize \\
\hline NC 12 & Davie & Piedmont & Karl & Commercialc $^{c}$ & Conventional & Maize \\
\hline NC 13 & Wayne & Coastal & Wakefield & 1 & Conventional & Maize \\
\hline NC 14 & Wayne & Coastal & Wakefield & 1 & Conventional & Maize \\
\hline NC 15 & Wayne & Coastal & Wakefield & 1 & Conventional & Maize \\
\hline NC 16 & Wayne & Coastal & Wakefield & 2 & Conventional & Maize \\
\hline NC 17 & Wayne & Coastal & Wakefield & 2 & Conventional & Maize \\
\hline NC 18 & Wayne & Coastal & Coker 916 & 3 & Conventional & Soybean \\
\hline NC 19 & Wayne & Coastal & Wakefield & 4 & Conventional & Soybean \\
\hline NC 20 & Wayne & Coastal & Wakefield & 4 & Conventional & Soybean \\
\hline NC 21 & Wayne & Coastal & Wakefield & 4 & Conventional & Soybean \\
\hline NC 22 & Wayne & Coastal & Wakefield & 4 & Conventional & Soybean \\
\hline $\mathrm{NC} 23$ & Wayne & Coastal & Wakefield & 4 & Conventional & Soybean \\
\hline NC 24 & Wayne & Coastal & Coker 916 & 5 & No-till & Maize \\
\hline NC 25 & Wayne & Coastal & Coker 916 & 5 & No-till & Maize \\
\hline NC 26 & Wayne & Coastal & Coker 916 & 5 & No-till & Maize \\
\hline NC 27 & Wayne & Coastal & Coker 916 & 5 & No-till & Maize \\
\hline NC 28 & Wayne & Coastal & Coker 916 & 5 & No-till & Maize \\
\hline NC 29 & Wayne & Coastal & Coker 916 & 5 & No-till & Maize \\
\hline NC 30 & Wayne & Coastal & Wakefield & 6 & Conventional & Soybean \\
\hline NC 31 & Wayne & Coastal & Wakefield & 7 & Conventional & Maize \\
\hline NC 32 & Wayne & Coastal & Wakefield & 7 & Conventional & Maize \\
\hline NC 33 & Wayne & Coastal & Wakefield & 7 & Conventional & Maize \\
\hline NC 34 & Wayne & Coastal & Wakefield & 7 & Conventional & Soybean \\
\hline NC 35 & Wayne & Coastal & Wakefield & 7 & Conventional & Soybean \\
\hline NC 36 & Wayne & Coastal & Wakefield & 7 & Conventional & Soybean \\
\hline NC 37 & Wayne & Coastal & Wakefield & 7 & Conventional & Soybean \\
\hline NC 38 & Wayne & Coastal & Coker 916 & 8 & Conventional & Soybean \\
\hline NC 39 & Wayne & Coastal & Wakefield & 9 & Conventional & Soybean \\
\hline NC 40 & Wayne & Coastal & Wakefield & 9 & Conventional & Soybean \\
\hline NC 41 & Wayne & Coastal & Wakefield & 9 & Conventional & Soybean \\
\hline $\mathrm{NC} 42$ & Wayne & Coastal & Wakefield & 9 & Conventional & Soybean \\
\hline NC 43 & Wayne & Coastal & Wakefield & 9 & Conventional & Soybean \\
\hline $\mathrm{NC} 44$ & Wayne & Coastal & Coker 916 & 10 & No-till & Maize \\
\hline NC 45 & Wayne & Coastal & Coker 916 & 10 & No-till & Maize \\
\hline NC 46 & Wayne & Coastal & Coker 916 & 10 & No-till & Maize \\
\hline NC 47 & Wayne & Coastal & Coker 916 & 10 & No-till & Maize \\
\hline NC 48 & Wayne & Coastal & Coker 916 & 10 & No-till & Maize \\
\hline NC 49 & Wayne & Coastal & Wakefield & 11 & Conventional & Maize \\
\hline NC 50 & Wayne & Coastal & Wakefield & 11 & Conventional & Maize \\
\hline NC 51 & Wayne & Coastal & Wakefield & 11 & Conventional & Maize \\
\hline NC 52 & Wayne & Coastal & Wakefield & 11 & Conventional & Maize \\
\hline NC 53 & Wayne & Coastal & Wakefield & 11 & Conventional & Maize \\
\hline NC 54 & Wayne & Coastal & Wakefield & 12 & No-till & Maize \\
\hline NC 55 & Wayne & Coastal & Wakefield & 12 & No-till & Maize \\
\hline NC 56 & Wayne & Coastal & Wakefield & 12 & No-till & Maize \\
\hline NC 57 & Wayne & Coastal & Wakefield & 12 & No-till & Maize \\
\hline NC 58 & Wayne & Coastal & Coker 916 & 13 & Conventional & Soybean \\
\hline NC 59 & Wayne & Coastal & Coker 916 & 13 & Conventional & Soybean \\
\hline NC 60 & Wayne & Coastal & Coker 916 & 13 & Conventional & Soybean \\
\hline NC 61 & Wayne & Coastal & Wakefield & 14 & No-till & Maize \\
\hline NC 62 & Wayne & Coastal & Wakefield & 14 & No-till & Maize \\
\hline NC 63 & Wayne & Coastal & Wakefield & 14 & No-till & Maize \\
\hline NC 64 & Wayne & Coastal & Wakefield & 14 & No-till & Maize \\
\hline NC 65 & Wayne & Coastal & Coker 916 & 14 & Conventional & Soybean \\
\hline NC 66 & Wayne & Coastal & Coker 916 & 14 & Conventional & Soybean \\
\hline
\end{tabular}

a Oasis $\times$ Coker $762 \mathrm{~F}_{2}$ progeny.

${ }^{\mathrm{b}}$ Coker $8012 \times$ Gore $\mathrm{F}_{2}$ progeny.

${ }^{c}$ Commercial field.

${ }^{\mathrm{d}}$ Conventional tillage consisted of chisel plow and soil disc prior to planting. 
Farming in Wayne County, NC, in the eastern part of the state where the majority of wheat production occurs. The fields at the center were adjacent to each other, with different combinations of crop rotation and tillage types in each field. Two isolates of F. graminearum (R-6914), (R-6925), an isolate of $F$. culmorum (R-6565), and an isolate of $F$. avenaceum (R-5314) were obtained from the Pennsylvania State University Fusarium Center (University Park, PA) for comparison to the North Carolina isolates. Seeds from infected wheat heads were surface sterilized in $0.525 \%$ sodium hypochlorite for $1 \mathrm{~min}$ and then washed for $1 \mathrm{~min}$ in sterile distilled water. Surface sterilized seeds were plated on synthetic nutrient agar (SNA) as described by Nirenberg (10). SNA is a low-nutrient medium that reduces mutations in Fusarium species. Single-spore isolations as described by Snyder and Hansen (8) were performed for each sample.

Growth rate was measured for each isolate in a randomized complete block design. A 5-mm agar plug was taken from each isolate and placed in the center of an $80 \mathrm{~mm}$ diameter Petri dish containing 15 $\mathrm{ml}$ of SNA. Three replicates of each isolate were incubated at $25 / 22^{\circ} \mathrm{C}$ (day/night) for 7 days. Cultures were exposed to $12 \mathrm{~h}$ of fluorescent light per day. Light intensity averaged $45.9 \mu \mathrm{mol} \mathrm{s} \mathrm{m}^{-1}$ and was measured using a Li-189 Quantum/Radiometer/Photometer (Licor, Lincoln, NE). Measurements of radial growth were taken at 3, 5, and 7 days, and $\log$ transformed. An average rate of growth per day was calculated for each isolate prior to final analysis. Incubator shelves functioned as blocks. The entire test was performed twice.

Pathogenicity testing was performed in the greenhouse using wheat cultivars 'Cardinal' (PI365440), 'Wakefield' (PI547040), and 'Caldwell' (CItr17897). A completely random design was used with 70 isolates $\times 3$ cultivars $\times 3$ plants per cultivar. Seeds were vernalized prior to planting by placing them in moist paper towels that were kept at $5^{\circ} \mathrm{C}$ for 8 weeks. The vernalized seeds were grown in pot- ting soil under greenhouse conditions. Plants were exposed to $12 \mathrm{~h}$ of light per day at an average intensity of $285 \mu \mathrm{mol} \mathrm{s}{ }^{-2}$ $\mathrm{m}^{-1}$. Individual wheat heads were inoculated in the greenhouse at mid-anthesis. Inoculations were performed using a micropipettor to apply a $20 \mu \mathrm{l}$ drop of inoculum at a concentration of approximately 1,000 macroconidia in the center region of one central spikelet per plant. Plastic bags were misted with sterile water and placed over inoculated heads for 5 days. This technique provided the moisture required for infection and prevented movement of isolates to other plants. Controls used sterile water in place of inoculum. The percentage of blighted head tissue was recorded at 10 and 20 days after inoculation. The visual scale published by Stack and McMullen (16) was used as a reference for determining percent FHB infection. Due to differences in maturity, inoculations of the three cultivars occurred at different times. Greenhouse tests using 70 isolates were performed twice and a smaller test of the five most and least aggressive isolates was performed a third time and subsequently analyzed for in vivo DON production. Statistical analysis was performed using SAS release 6.12 (SAS Institute, Cary, NC).

RAPD analysis. Single-spore isolates from each original field isolate were grown for 7 days in $1.5 \mathrm{ml}$ micro centrifuge tubes containing $500 \mu \mathrm{l}$ Yeast-Malt (YM) broth (3 g yeast extract, $3 \mathrm{~g}$ malt extract, $5 \mathrm{~g}$ peptone, $10 \mathrm{~g}$ dextrose per liter, Difco, Detroit MI). After 7 days, $500 \mu$ of sterile Tris-EDTA pH 8.0 (TE) was added and tubes were boiled at $100^{\circ} \mathrm{C}$ for $10 \mathrm{~min}$. Tubes were then cooled on ice for $10 \mathrm{~min}$ and spun at $13,000 \mathrm{rpm}$ for $10 \mathrm{~min}$. The aqueous fraction containing DNA was removed and placed in a new tube. Samples were diluted by mixing $3 \mu \mathrm{l}$ of the aqueous DNA fraction with $97 \mu \mathrm{l}$ of sterile water.

Each RAPD reaction consisted of $15 \mu \mathrm{l}$ volume composed of $5 \mu$ diluted DNA, 1.5 $\mu \mathrm{T} \mathrm{Taq}$ polymerase buffer (Promega, Madison WI), $0.9 \mu \mathrm{l} 25 \mathrm{mM} \mathrm{MgCl} 2,1.2 \mu \mathrm{l} 1.25$ $\mathrm{mM}$ dNTPs, $1.2 \mu \mathrm{l}$ 100X unacetylated bovine serum albumin (NEB, Beverly, MA), 30 ng primer (Operon Technologies, Alameda, CA, and University of British Columbia, Vancouver), and $0.2 \mu \mathrm{l} \mathrm{Taq}$ polymerase (Promega). Reactions were performed using 96-well plates and a PTC100 thermocycler (MJ Research, Watertown, MA). Cycle parameters consisted of $1 \mathrm{~min}$ at $92^{\circ} \mathrm{C}$, then $1 \mathrm{~min}$ at $35^{\circ} \mathrm{C}$, followed by $2 \mathrm{~min}$ at $72^{\circ} \mathrm{C}$ repeated for a total of 40 cycles. Samples were run out in $1.5 \%$ agarose gels at $100 \mathrm{~V}$ for approximately $4 \mathrm{~h}$ and visualized using EtBr and UV fluorescence. Twenty primers were screened on eight randomly selected isolates. The five primers producing the highest levels of polymorphism, UBC28 (5'-CCGGCC TTAA-3'), OPB15 (5'-GGAGGGTGTT3'), OPQ4 (5'-AGTGCGCTGA-3'), OPL10 (5'-TGGGAGATGG-3'), S12 (5'-CTG GGTGAGT-3'), OPM5 (5'-GGGAAC GTGT-3'), were used for analysis of the 70 isolates. Isolates were screened twice with each primer and repeatable polymorphisms were scored as 1 for presence of a band and 0 for absence.

Multiple regression analysis. A multiple regression model was developed using disease rating as the dependent variable with the wheat cultivar from which the isolate was collected, collection location, plot, previous crop, tillage conditions, in vitro rate of growth, and in vitro production of DON and zearalenone as independent variables. The categorical values (location, cultivar, etc.) were used as dummy variables (18) and no consideration should be given to the numbers assigned to each condition (e.g., conventional versus no tillage). Interpretation is limited to the detection of differences only. The maxr and Mallow's CP functions were used to aid in model development.

Cluster analysis. Cluster analysis of isolates utilized mean ratings of the phenotypic characteristics of toxin production, rate of growth, and disease rating to form a dendrogram. The NTSYS numerical taxonomy program (Exeter Software, Setauket, NY) (13) was used for analysis. The SIMINT function for quantitative data was used to form a covariance matrix and the

Table 2. Means and ranges of in vitro growth, in vitro levels of deoxynivalenol (DON) and zearalenone produced, and disease rating of the four typed Fusarium isolates compared to the 66 Fusarium graminearum isolates collected in North Carolina

\begin{tabular}{|c|c|c|c|c|c|c|c|}
\hline Variable & FA $^{\mathrm{e}} 5314$ & FC $^{\mathrm{f}} 6565$ & FG $^{\mathrm{g}} 6914$ & FG $^{\mathrm{h}} 6925$ & NC mean & NC minimum & NC maximum \\
\hline In vitro growth (mm/day) & 3.4 & 3.7 & 7.2 & 5.1 & 4.7 & 0.9 & 11.4 \\
\hline DON $27-4-27^{\circ} \mathrm{C}^{\mathrm{a}}(\mathrm{ppm})$ & 401 & 1,341 & 952 & 412 & 641 & 0 & 7,176 \\
\hline DON $27^{\circ} \mathrm{C}^{\mathrm{b}}(\mathrm{ppm})$ & 734 & 1,987 & 4,087 & 643 & 736 & 0 & 8,972 \\
\hline Zearalenone $27-4-27^{\circ} \mathrm{C}^{\mathrm{c}}(\mathrm{ppm})$ & 5.6 & 0.2 & 10 & 1.7 & 26 & 0 & 355 \\
\hline Zearalenone $27^{\circ} \mathrm{C}^{\mathrm{d}}(\mathrm{ppm})$ & 33 & 0 & 0 & 10 & 12 & 0 & 87 \\
\hline Disease Rating (mean percent area) & 13 & 76 & 67 & 64 & 51 & 0 & 100 \\
\hline
\end{tabular}

${ }^{\text {a }}$ In vitro DON cultures incubated at $27^{\circ} \mathrm{C}$ for 7 days, then $4^{\circ} \mathrm{C}$ for 5 days, followed by 18 days at $27^{\circ} \mathrm{C}$.

${ }^{\mathrm{b}}$ In vitro DON cultures incubated at $27^{\circ} \mathrm{C}$ for 30 days.

${ }^{c}$ In vitro zearalenone cultures incubated at $27^{\circ} \mathrm{C}$ for 7 days, then $4^{\circ} \mathrm{C}$ for 5 days, followed by 18 days at $27^{\circ} \mathrm{C}$.

${ }^{\mathrm{d}}$ In vitro zearalenone cultures incubated at $27^{\circ} \mathrm{C}$ for 30 days.

e Typed isolate of $F$. avenaceum.

${ }^{\mathrm{f}}$ Typed isolate of $F$. culmorum.

$\mathrm{g}$ Typed isolate of $F$. graminearum.

${ }^{\text {h }}$ Typed isolate of $F$. graminearum. 
dendrogram was generated using the SAHN clustering function. Cluster analysis was also performed on genotypic data collected from RAPD analysis. Polymorphism data were used to form a dice coefficient matrix using Win-Boot (IRRI, Manila, Philippines) (19). The resulting matrix was used to form a dendrogram using the SAHN clustering function of NTSYS.

Toxin analysis. Isolates for in vitro toxin analysis were grown on rice medium consisting of $5 \mathrm{~g}$ rice with $3 \mathrm{ml}$ deionized water. All 70 isolates were tested for in vitro DON and zearalenone. The medium was placed in $20 \mathrm{ml}$ screw-capped vials and autoclaved for $30 \mathrm{~min}$ before inoculation. Twelve vials were inoculated per isolate. Six were incubated after inoculation for 30 days at $27^{\circ} \mathrm{C}$. The remaining six were incubated 7 days at $27^{\circ} \mathrm{C}$, followed by 5 days at $4^{\circ} \mathrm{C}$, and 18 days at $27^{\circ} \mathrm{C}$. At 30 days, all cultures were frozen until extraction.

Fifteen $\mathrm{ml}$ of $84 \%$ acetonitrile were added to six cultures of each isolate (three taken from each of the two temperature treatments). A 5-ml sample of each culture extract was passed through a cleanup column and collected. Cleanup columns were composed of a filter disk pressed into the bottom of a $5 \mathrm{ml}$ syringe barrel. One $\mathrm{g}$ of 1:3 C18RP silica gel:aluminum oxide was dispensed into the syringe barrel. A filter disk was placed on top of the packing and compressed. Columns were heated overnight at $60^{\circ} \mathrm{C}$ and stored in a desiccator until use.

In vitro DON was quantified by capillary gas chromatography (Model GC-14A, Shimadzu Scientific, Baltimore, MD) using techniques described by Tacke and Casper (17). Electron capture was utilized and $\mathrm{N}_{2}$ at $4 \mathrm{ml} / \mathrm{min}$ was the carrier gas. The detector and injector were operated at $300^{\circ} \mathrm{C}$ and $250^{\circ} \mathrm{C}$, respectively. The oven was programmed from 200 to $260^{\circ} \mathrm{C}$ at $4^{\circ} \mathrm{C}$ per min. Data were recorded and calculated relative to pure DON standards (Sigma Chemical, St. Louis, MO) using a microcomputer equipped with SS420 analog/digital converter boards and the EZCHROM 6.2 chromatography software system. Analysis was performed on a $30-\mathrm{m}$ Megabore (0.53 mm) DB-1701 fused silica column (J \& W Scientific, Folson, CA). Solvent was dried under $\mathrm{N}_{2}$, and purified fungal extract was derivatized with $100 \mu \mathrm{l}$ Tri-Sil TBT (Pierce, Rockford, IL) for $1 \mathrm{~h}$ at $60^{\circ} \mathrm{C}$. After cooling, $1 \mathrm{ml}$ hexane was added and samples vortexed. One $\mathrm{ml}$ deionized water was added and vortexed for $1 \mathrm{~min}$. The upper organic layer was taken and a $2 \mu \mathrm{l}$ volume was injected onto the column.

Wheat heads infected with the five most aggressive and five least aggressive isolates were collected from greenhouse tests, threshed in a single head thresher, and analyzed individually for in vivo DON.
Samples were weighed and ground in an electric coffee grinder and a 2:1 (solvent:sample) ratio of $84 \%$ acetonitrile was added to each sample. Subsequent sample preparation and analyses were performed as described for in vitro DON analysis.

In vivo DON for the Wakefield samples was quantified by ELISA with an upper limit of 5 ppm for Tests 1 and 2. All samples from the most aggressive isolates exceeded this limit, therefore in vivo DON for the Cardinal and Caldwell samples were quantified using the previously described gas chromatography procedure. Gas chromatography was used in the third test of in vivo DON on all three cultivars.

In vitro analysis of zearalenone was performed using the six remaining cultures of each isolate. After incubation, $15 \mathrm{ml}$ of $70 \%$ methanol were added to all six. Extracts were analyzed by direct competitive enzyme-linked immunosorbent assay utilizing the Veratox Zearalenone Quantitative Test Kit (Neogen, Lansing, MI). Samples were read on a EL301 strip reader using a $650 \mathrm{~nm}$ filter (Bio-Tek Instruments, Winooski, VT).

\section{RESULTS}

All isolates collected in North Carolina were identified as F. graminearum based

A.

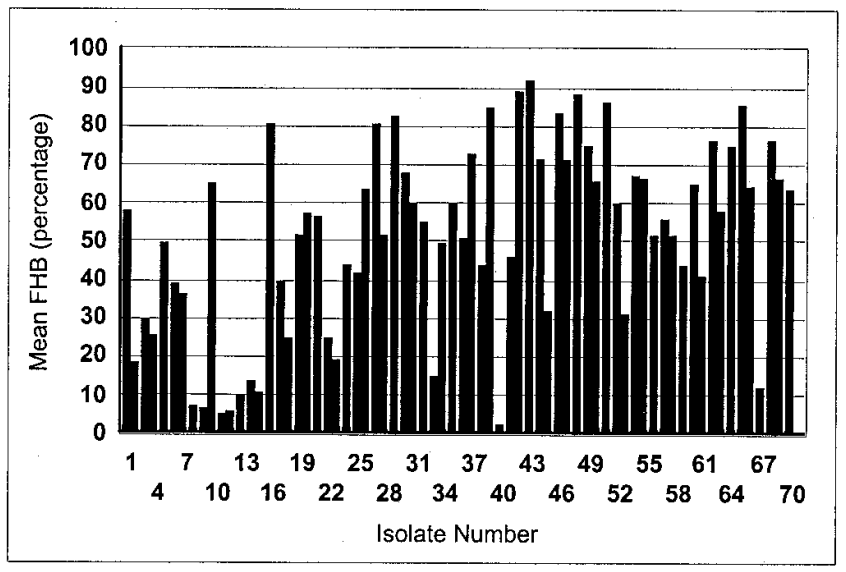

B.
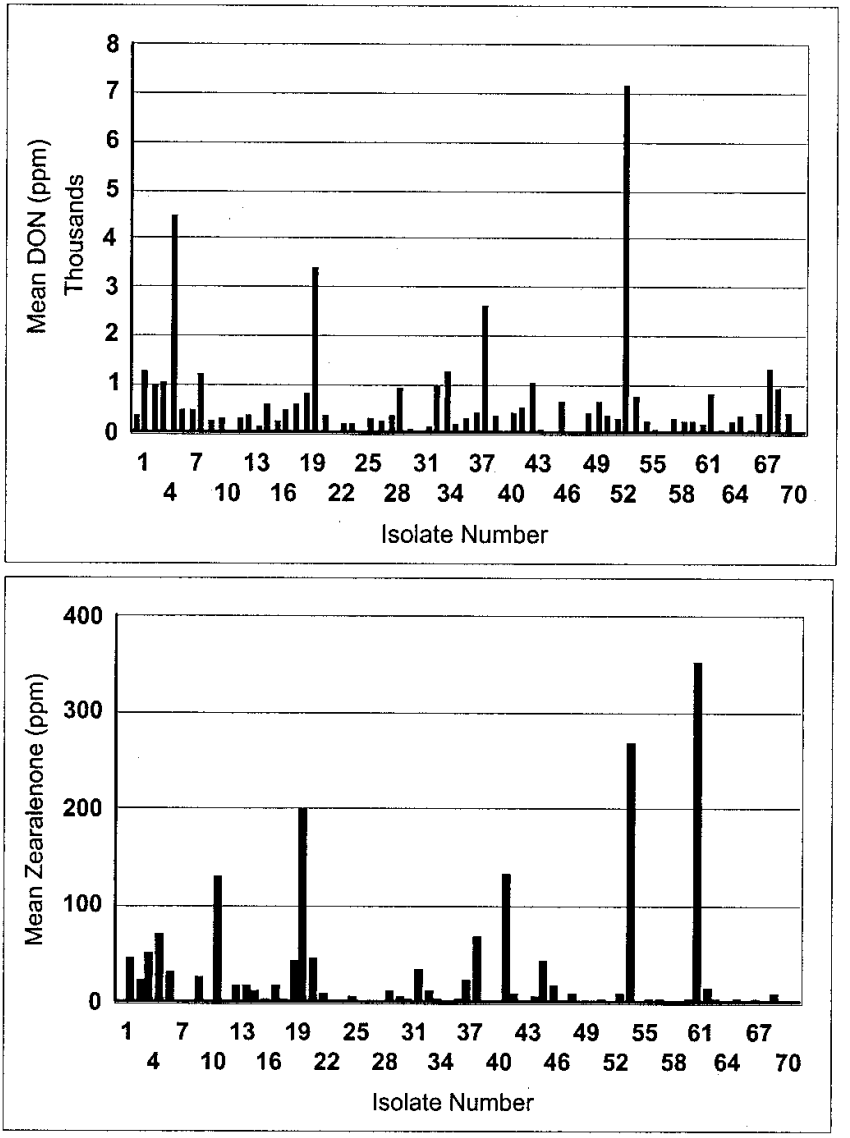

Fig. 1. Fusarium head blight rating and in vitro deoxynivalenol (DON) and zearalenone produced by 70 isolates of Fusarium species on three wheat cultivars. A, Mean percentage of blighted spikelets. $\mathbf{B}$, Mean level of in vitro DON in ppm. C, Mean level of in vitro zearalenone in ppm. 
on visual characteristics as described by Nelson et al. (8). Each isolate was compared to the typed isolates from the Pennsylvania State University Fusarium Center. Disease rating, in vitro, and in vivo toxin production varied greatly among isolates (Table 2, Figure 1). The $F$. graminearum isolates collected in North Carolina were similar to the two typed isolates of $F$. graminearum in pathogenicity, growth rate, and production of in vitro DON and zearalenone (Table 2). Of the four typed isolates, $F$. culmorum and $F$. graminearum were more pathogenic on wheat than $F$. avenaceum.

Disease ratings differed significantly among the three cultivars tested $(p<$ $0.0001)$. Mean disease severities on Wakefield, Cardinal and Caldwell were 51\%, $41 \%$ and $60 \%$ respectively. No symptoms of disease occurred in the control inoculations. Significant differences between greenhouse tests occurred $(p<0.02)$; however, mean disease scores among tests were highly correlated $(r=0.96, p<0.0001)$ when mean disease ratings were compared for each isolate. Ranking of isolates based on pathogenicity remained constant in both tests. Analysis of the three greenhouse pathogenicity tests involving the five most and least aggressive isolates demonstrated no significant differences among tests $(p<$ 0.224 ), and mean disease scores between tests were highly correlated $(r=0.98, p<$ $0.0001)$ when compared on a per isolate basis.

Significant differences in pathogenicity were found among isolates from within a single plot, within a single field, and within a collection location (Table 3 ). No differences in pathogenicity were found among isolates due to tillage or previous crop.

In vitro DON at the constant temperature of $27^{\circ} \mathrm{C}$ was highly correlated to in vitro DON production at the $27^{\circ} \mathrm{C}-4^{\circ} \mathrm{C}$ $27^{\circ} \mathrm{C}$ temperature regime $(r=0.86, p<$ $0.0001)$. In vitro and in vivo DON production were not correlated.

The two temperature regimes for in vitro zearalenone production were correlated $(r$ $=0.31, p<0.0001)$, with the variable temperature regime producing a higher mean level $(26 \mathrm{ppm})$ of zearalenone than the constant temperature regime (12 $\mathrm{ppm})$. The standard deviation of the variable temperature regime was much higher (59.2) compared to the constant temperature regime (18.7).

No significant differences were found among the two groups of most and least aggressive isolates in terms of in vivo

Table 3. Analysis of variance of differences in disease rating in a greenhouse test among 66 isolates of Fusarium graminearum in relation to collection location, field, plot within a field, tillage conditions, and previous crop

\begin{tabular}{lrcc}
\hline Variable & df & Type III mean square & $\boldsymbol{P r}>\boldsymbol{F}$ \\
\hline Collection Location & 4 & 6.94 & 0.0001 \\
Field & 6 & 4.32 & 0.0001 \\
Plot & 12 & 2.23 & 0.0001 \\
Tillage $^{\mathrm{a}}$ & 1 & 0.005 & 0.138 \\
Previous Crop $^{\mathrm{b}}$ & 1 & 0.035 & 0.112 \\
Error $^{-}$ & 2,522 & 0.077 & \\
\hline
\end{tabular}

a Tillage was conventional or no-till.

${ }^{\mathrm{b}}$ Previous crop was maize or soybean.

\section{MW FA FC FG FG 1234456789101112131415161718192021222324 MW}

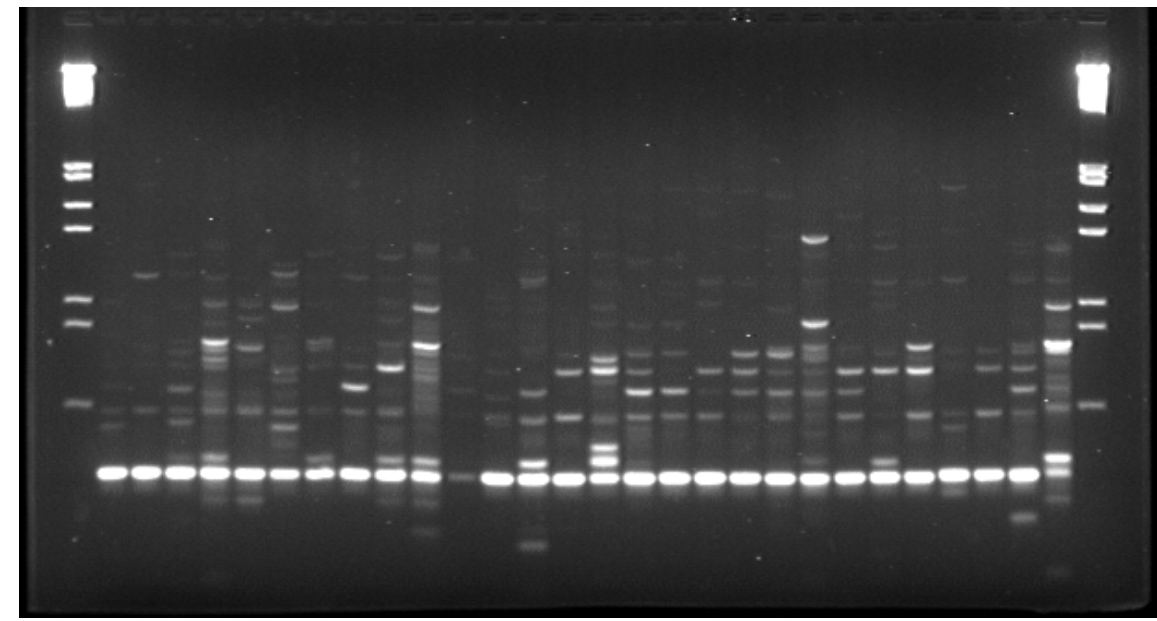

Fig. 2. Randomly Amplified Polymorphic DNA profile produced by Operon primer OPB15. Lane 1 is Molecular Marker III (Boeringer, Mannheim, Germany), lane 2 is Fusarium avenaceum (R-5314), lane 3 is F. culmorum (R-6565), lane 4 and 5 are F. graminearum (R-6914 and R-6925), and lanes 629 are North Carolina F. graminearum isolates 1 to 24 , respectively.
DON production, nor were there significant differences among cultivars for this toxin. In vivo DON was highly variable among individual replications of seedlots, making analysis of trends difficult. Weakly pathogenic isolates tested did produce in vivo DON when averaged over several replications, with the least aggressive isolate producing $113 \mathrm{ppb}$ DON on average. The mean level of symptoms produced by this isolate was $2.3 \%$ bleaching on wheat heads.

Multiple regression analysis using in vitro growth, in vitro DON and zearalenone production, collection location, the wheat cultivar from which an isolate originated, plot, tillage conditions, and previous crop as independent variables and disease rating as the dependent variable produced a cumulative $R^{2}=0.27$ with in vitro rate of

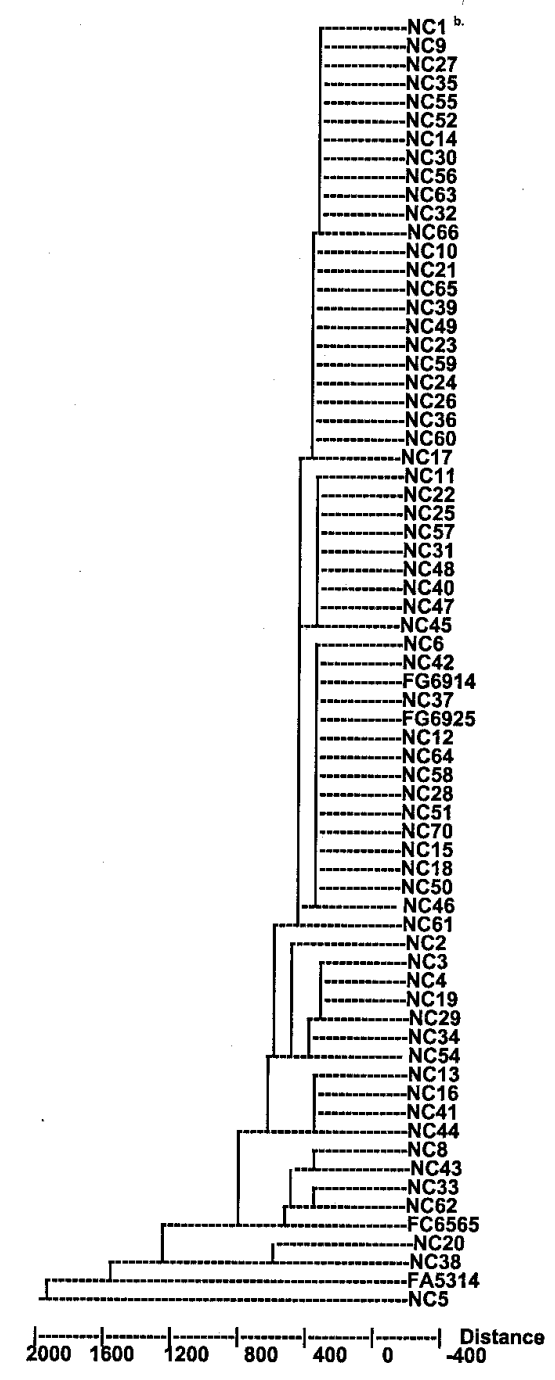

Fig. 3. Cluster analysis of 70 Fusarium spp. isolates based on disease rating, in vitro deoxynivalenol and zearalenone production, rate of isolate growth, location where isolate was collected, and cultivar of wheat where isolate originated. $\mathrm{a}=$ Phenotypic distance; $\mathrm{b}=$ Isolate number. 
making the greatest contribution (0.14) to this value. RAPD analysis demonstrated a large amount of genotypic variability among the isolates (Fig. 2). Ninety-six polymorphisms were repeatable in two tests of each primer.

The phenotypic traits of mean disease scores, mean level of production of in vitro DON and zearalenone, and mean rate of growth for each isolate were used to form the dendrogram in Figure 3. Genetic data from the RAPD analysis were used to form the dendrogram presented in Figure 4 and suggests genotypic diversity was greater than phenotypic diversity among the characters measured in this population. Some isolates collected from the same plot were genetically similar such as NC 3 and NC 5 , while others from the same plot were divergent such as NC 4. The typed isolates of $F$. graminearum were very similar to each other, both phenotypically and genotypically. In comparison to the North Carolina isolates, the typed F. graminearum isolates were more similar genetically to North Carolina isolates collected in the mountain region, while phenotypically there were more similar to the North Carolina isolates collected in the eastern region of the state.

\section{DISCUSSION}

These data indicate the $F$. graminearum population in North Carolina is diverse. Some isolates produced on average 80 to $100 \%$ disease severity on the three wheat cultivars tested, whereas others were much less virulent (Fig. 1). Diversity among isolates for pathogenicity was found within a single plot, a single field and location, and across North Carolina. High levels of genotypic diversity within a plot, a field, and a location were found in the RAPD analysis, suggesting sexual reproduction is occurring within the surveyed $F$. graminearum population. Therefore, new genotypes are constantly being produced and diversity should remain high even in a limited spatial area.

Bowden and Leslie (3) hypothesize that high levels of genotypic diversity occurring in a small spatial area indicate several

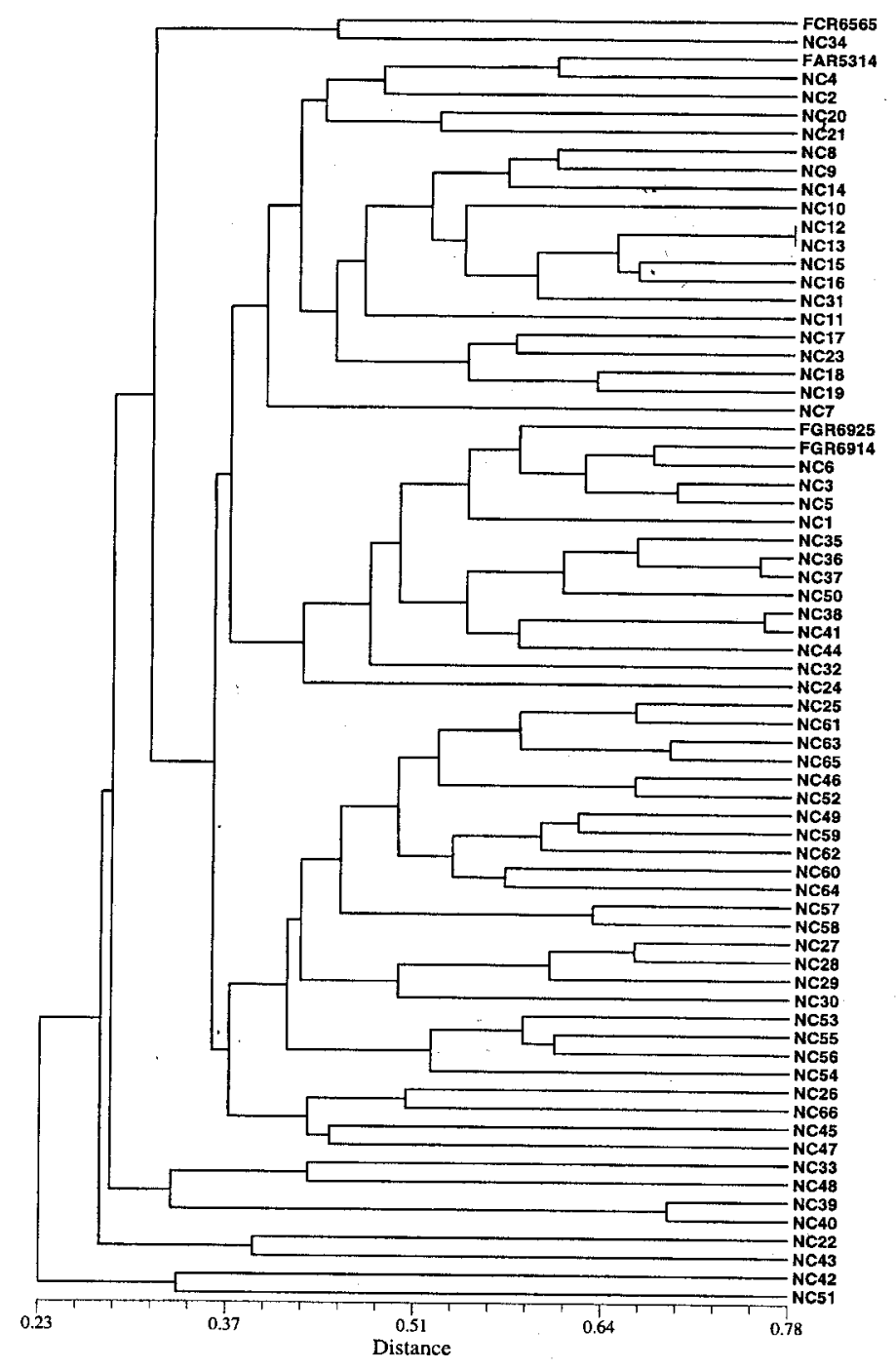

Fig. 4. Cluster analysis of genetic polymorphism data produced by 70 isolates of Fusarium spp. using the Randomly Amplified Polymorphic DNA technique.

independent infections occurred from diverse sources of inoculum, and the occurrence of multiple genotypes in a small area may provide opportunities for high levels of sexual recombination. Gibberella zeae, the perfect state of $F$. graminearum, is homothallic, and this may contribute to high levels of sexual reproduction. The data reported here indicate high levels of genotypic and phenotypic diversity can occur in an area where FHB has not been a severe problem.

Tillage conditions and previous crop did not have a significant effect on isolate diversity in regard to pathogenicity. These two factors, however, may have an impact on inoculum density by creating a greater reservoir of primary inoculum.

Data from this study indicate at least two components of the disease triangle, an aggressive pathogen and a susceptible host, are present in North Carolina. Warm, moist conditions can occur during the time wheat is susceptible to infection in North Carolina, so the question is raised as to why FHB epidemics occur infrequently in the state. To obtain the isolates used in this study, we had to search fields carefully to find plants showing symptoms of FHB or signs of the pathogen. Even though some isolates were highly aggressive and the host is probably at least moderately susceptible, the overall incidence of disease in a plot or field was well under $1 \%$. We suspect the inoculum density and timing of rainfall events may have prevented widescale epidemics of FHB in North Carolina. Reduced tillage wheat production has not been widely adopted as of yet in the state, and the relatively warm winters accelerate degradation of any surface debris after conventional tillage. We believe these factors have kept the inoculum levels of $F$. graminearum at low enough levels to prevent an epidemic.

Data presented here indicate the presence of a pathogen population that can generate high levels of FHB on susceptible cultivars of wheat, and members of this population are able to generate high levels of detrimental toxins. Data presented here on in vivo DON levels indicate plants with very low symptomatic expression of FHB can have detectable levels of in vivo DON. Based on these data, it may be advisable to periodically survey grain elevators for DON, even if epidemics have not occurred. The high levels of in vitro zearalenone produced by some isolates indicates further research on the levels of this toxin in harvested grain are warranted.

Further investigations into naturally occurring inoculum densities may be beneficial in determining factors that limit FHB epidemics in North Carolina. This information may be useful in determining the future threat of an epidemic in the state and allow researchers and extension personnel to address the problem in a timely manner. 


\section{ACKNOWLEDGMENTS}

The authors thank H. Edwards for assistance in toxin analysis, and M. Carson, J. Kolmer, C. Stuber, and B. Liu for technical advice.

\section{LITERATURE CITED}

1. Bai, G. H., and Shaner, G. 1994. Scab of wheat: prospects for control. Plant Dis. 78:760-765.

2. Bai, G. H., and Shaner, G. 1996. Variation in Fusarium graminearum and cultivar resistance to wheat scab. Plant Dis. 80:975-979.

3. Bowden, R. L., and Leslie, J. F. 1996. Diversity and sexuality in Gibberella zeae. Fusarium Head Scab: Global Status and Future Prospects. H. J. Dubin, L. Gilchrist, J. Reeves, and A. McNab, editors, CIMMYT, Mexico pp. 35-39.

4. Desjardins, A. E., Proctor, R. H., McCormick, S. P., and Hohn, T. M. 1996. Reduced virulence of trichothecene antibiotic-nonproducing mutants of Gibberella zeae in wheat field tests. Fusarium Head Scab: Global Status and Future Prospects. H. J. Dubin, L. Gilchrist, J. Reeves, and A. McNab, eds., CIMMYT, Mexico pp. 29-34.

5. Dill-Macky, R. 1996. Fusarium head blight: Recent epidemics and research efforts in the upper Midwest of the United States. Fusarium
Head Scab: Global Status and Future Prospects. H. J. Dubin, L. Gilchrist, J. Reeves, and A. McNab, eds., CIMMYT, Mexico.

6. Marasas, W. F. O. 1984. Toxigenic Fusarium Species, Identity and Mycotoxicology. Pennsylvania State University Press, University Park.

7. McMullen, M., Jones, R., and Gallenberg, D. 1997. Scab of wheat and barley: A reemerging disease of devastating impact. Plant Dis. 81:1340-1348.

8. Nelson, P. E., Toussoun, T. A., and Marasas, W. F. O. 1983. Fusarium Species: An Illustrated Manual for Identification. Pennsylvania State University Press, University Park.

9. Nicholson, P., Jenkinson, P., Rezanoor, H. N., and Parry, D. W. 1993. Restriction fragment length polymorphism analysis of variation in Fusarium species causing ear blight of cereals. Plant Pathol. 42:905-914.

10. Nirenberg, H. I. 1981. A simplified method for identifying Fusarium spp. occurring on wheat. Can. J. Bot. 59:1599-1609.

11. Ouellet, T., and Seifert, K. A. 1993. Genetic characterization of Fusarium graminearum strains using RAPD and PCR amplification. Phytopathology 83:1003-1007.

12. Parry, D. W., Jenkinson, P., and McLeod, L. 1995. Fusarium ear blight (scab) in small grain cereals - a review. Plant Pathol. 44:207-238.

13. Rohlf, J. F. 1992. NTSYS-pc: Numerica Taxonomy and Multivariate Analysis System. Version 1.70. Exeter Software, Setauket, NY.

14. Schilling, A. G. 1996. Characterization and differentiation of the cereal pathogens Fusarium culmorum and $F$. graminearum by PCR-based molecular markers. Ph.D. diss. University of Hohenheim, Germany.

15. Schroeder, H. W., and Christensen, J. J. 1963. Factors affecting resistance of wheat to scab caused by Gibberella zeae. Phytopathology 53:831-838.

16. Stack, R. W., and McMullen, M. P. 1995. A visual scale to estimate severity of Fusarium head blight in wheat. North Dakota State University Extension Service, PP-1095.

17. Tacke, B. K., and Casper, H. H. 1996. Determination of deoxynivalenol in wheat, barley, and malt by column cleanup and gas chromatography with electron capture detection. J. AOAC Int. 79:472-475.

18. Weisberg, S. 1980. Applied Linear Regression. John Wiley \& Sons, New York.

19. Yap, I. V., and Nelson, R. J. 1996. WinBoot: A program for performing bootstrap analysis of binary data to determine the confidence limits of UPGMA-based dendrograms. IRRI, Manila, Philippines. 